\section{Feature utilization of continuously varying attributes in visual pattern classification*}

\author{
LEONA S. AIKEN, $\uparrow$ Temple University, Philadelphia, Pa. 19122 \\ and DONALD BROWN, Purdue University, Lafayette, Ind. 47907
}

Feature utilization of continuously varying attributes was examined in the context of classification of random polygons, the collection of which contained no a priori classes based upon physical features. Ten Os sorted 60 eight-sided patterns into two through nine groups. One week later, each $O$ repeated three sorts and then placed 30 new patterns into the groups of his previous five-group sort. Comparison of groups across sessions primarily showed repetition of initial classification. Stepwise discriminant analyses were performed on Os' classes, predictors being physical measures of various pattern attributes. Significant predictors of all classifications were found, the two most prevalent predictor types being measures of compactness and jaggedness. LDFs based on original pattern classes showed generality to new patterns.

Implicit in any attempt to construct a psychophysics of form perception is the assumption that physical features of patterns must determine, or form the basis of, perceptual responses. What follows from this assumption is the necessary proposal that the human, in dealing with any multidimensional stimulus domain, systematically extracts from a set of events, attributes or features along which all of the stimulus events contained in a set vary. On the basis of these extracted features, some criterion or function is computed, upon which the $O$ bases his responses.

If an $O$ does behave in this manner, then it must be presumed that each element in a class of events is perceived in terms of relationship to the other class members. As has been frequently stressed by researchers in the area of pattern perception (Garner, 1962, 1966; Brown \& Owen, 1967), the perception of any unique event must be considered in terms of the total set of attribute aggregates from which the particular event arises, as well as the particular subset of which the individual stimulus is a member. Support for this notion has been found with both visual and auditory stimuli (Garner \& Clement, 1963; Handel \& Garner, 1966; Royer \& Garner, 1966).

Given the importance of class structure in the perception of a single event, a twofold question is raised concerning the nature of classification as it is evidenced in the perception of multidimensionally determined patterns: (1) What features or attributes of a stimulus domain are utilized by an $\mathrm{O}$ in the formulation of event classes,

*This research was supported by Research Grant HD-00909 from the National Institute of Child Health and Human Development.

tAddress: Department of Psychology, Templc University, Philadelphia, Pa. 19122. and (2) how are these features combined in the formulation of such classes?

In an early study of pattern classification, Beach (1964) found moderate support for the notion that events should be classified as a function of the conditional probability density of an event's arising from a class, given the distributions of all attributes which characterized the domain in question. In a similar fashion, Rodwan and Hake (1964), proposing the linear discriminant as a model for the classification of events, suggested that a "concept (or object class) can be defined as a region in an $\mathrm{n}$ space [p. 390]." The linear discriminant has since been successfully applied to the classification of marginally discriminable stimuli (Rodwan, 1964, 1965), of random vs schematic patterns (Mavrides \& Brown, 1970), and of patterns arising from two schematic classes (Aiken \& Brown, 1970).

In an attempt to uncover the nature of observer pattern-classification strategies, Imai and Garner (1965) investigated differential attribute usage under conditions of both free and constrained classification, finding preference for specific attributes to be evidenced by Os, sorting time varying with attribute discriminability. Imai (1966) showed that Os tend to construct numerically balanced categories, with classes being primarily differentiated in terms of single attributes. Imai and Garner (1968) found this same predominance of single-attribute classification in two other types of classification tasks. More recently, Handel and Preusser (1969) found that attribute usage in free classification differed as a function of simultaneous vs sequential presentation of patterns, with attribute choice varying as a function of attribute presentation. While in the aforementioned studies, attributes have been binary or trinary, Wing and Bcvan (1969) employed stimuli which varied in eight, six, four, and two values of four attributes, finding the predominant strategy again to be single-attribute usage, or the hierarchical use of two attributes as predominant strategies. Lastly, Bersted, Brown, and Evans (1969) have shown that when patterns arising from several schematic clusters are sorted by Os, more classes than the actual number of pattern clusters are generated.

With a few exceptions (Bersted et al 1969; Mavrides \& Brown, 1970; Aiken \& Brown, 1970), these studies of pattern classification have involved stimuli comprised of discretely varying attributes. The results of such studies are therefore difficult to relate to current findings in psychophysical studies of multidimensional pattern perception where physical attributes have been varied in a continuous fashion (e.g., Aiken \& Brown, 1969a, 1969b, 1969c; Behrman \& Brown, 1968; Brown \& Andrews, 1968; Brown \& Brumaghim, 1968; Brumaghim \& Brown, 1968; Fenker \& Brown, 1969; Forsy th \& Brown, 1967, 1968; Stenson, 1968). The present study was undertaken to examine the twofold question of attribute choice and combination in pattern classification posed herein, employing the same stimulus domain used in previous psychophysical investigations of pattern perception in order to allow comparison of feature utilization in a classification context with that found in the context of previous psychophysical investigations.

\section{METHOD}

\section{Patterns}

Patterns consisted of two samples, $\mathrm{N}=60$, and $\mathrm{N}=30$ (see Fig. 1), of

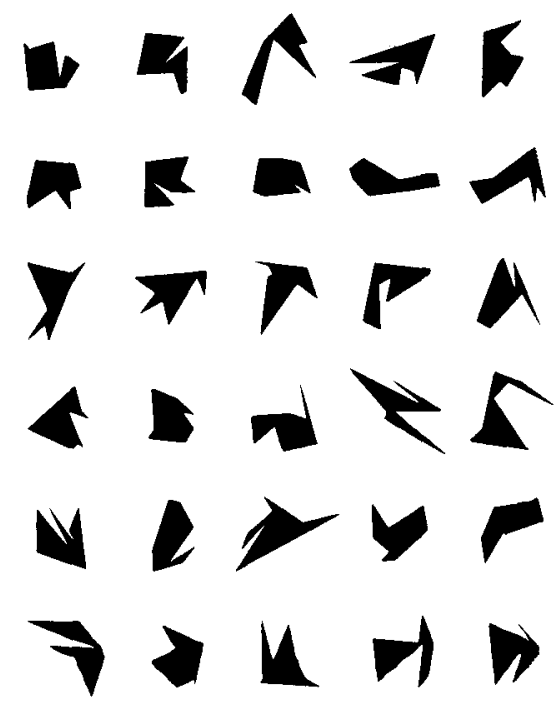

Fig. 1. Sample of patterns used in ex. periment. 
Table 1

Physical Measures for Selection of Stimuli

\begin{tabular}{|c|c|c|c|c|c|c|c|c|}
\hline \multirow{2}{*}{$\begin{array}{l}\text { Physical } \\
\text { Measure } 1 \\
\end{array}$} & \multirow{2}{*}{$\begin{array}{c}\text { Factor } \\
\text { Represented } \\
\end{array}$} & \multirow{2}{*}{$\begin{array}{c}\text { Factor } \\
\text { Loading } \\
\end{array}$} & \multirow{2}{*}{$\begin{array}{c}\text { Rank of } \\
\text { Factor } \\
\text { Loading } \\
\end{array}$} & \multicolumn{5}{|c|}{$\begin{array}{l}\text { Intercorrelation of Criterion } \\
\text { Measures A cross } 200 \text { Eight-Sided Patterns }\end{array}$} \\
\hline & & & & PM2X & $\mathbf{A}_{31}$ & $\mathrm{~V} / \mathrm{H}$ & CGPX & CGPY \\
\hline $\mathbf{P}_{\mathrm{M} 2 \mathrm{X}}$ & Compactness & -.90 & 2 & -- & -.177 & -.055 & -.136 & .024 \\
\hline$A_{3 I}$ & Jaggedness & -.90 & 1 & & -- & .059 & -.011 & -.058 \\
\hline $\mathrm{V} / \mathrm{H}$ & Elongation & .92 & 1 & & & -- & -.069 & .026 \\
\hline CGPX & Horizontal Skew & -.94 & 1 & & & & -- & -.084 \\
\hline CGPY & Vertical Skew & -.94 & 1 & & & & & -- \\
\hline
\end{tabular}

$I_{M e a s u r e:} P_{M 2 X}=$ maximum second perimeter moment of $X, A_{3 I}=$ third moment of interior angles, $V / H=$ ratio of vertical to horizontal extent, $C G_{P X}=X$ coordinate of the perimeter center of gravity, $C_{P Y}=Y$ coordinate of the perimeter center of gravity.

Table 2

Criterion Statistics of Two Samples 1

\begin{tabular}{|c|c|c|c|c|c|c|c|c|}
\hline & & \multirow{2}{*}{$\begin{array}{l}\text { Mean } \\
\text { Vector }\end{array}$} & \multirow{2}{*}{$\begin{array}{l}\text { Variance } \\
\text { Vector }\end{array}$} & \multicolumn{5}{|c|}{ Correlation of Measures } \\
\hline & & & & PM2X & A 31 & $\mathrm{~V} / \mathrm{H}$ & CGPX & CGPY \\
\hline \multicolumn{9}{|c|}{ Sample 1} \\
\hline \multirow[t]{5}{*}{ Measure: } & $\mathbf{P}_{\mathbf{M} 2 \mathrm{X}}$ & .08 & 1.00 & -- & -.07 & -.10 & .00 & -.13 \\
\hline & $\mathrm{A}_{3 \mathrm{I}}$ & .03 & .95 & & -- & -.16 & -.06 & .11 \\
\hline & $\mathrm{V} / \mathrm{H}$ & -.04 & .99 & & & -- & -.13 & .06 \\
\hline & $\mathrm{CG}_{\mathrm{PX}}$ & -.11 & .98 & & & & - & -.11 \\
\hline & $\mathrm{CG}_{\mathrm{PY}}$ & -.07 & 1.01 & & & & & -- \\
\hline \multicolumn{9}{|c|}{ Sample 2} \\
\hline \multirow[t]{5}{*}{ Measure: } & $\mathrm{P}_{\mathrm{M} 2 \mathrm{X}}$ & .12 & 1.13 & -- & -.05 & -.28 & -.02 & .29 \\
\hline & $A_{31}$ & .04 & 1.02 & & -- & .02 & .32 & .02 \\
\hline & $\mathrm{V} / \mathrm{H}$ & -.21 & .93 & & & -- & -.14 & .02 \\
\hline & CGPX & -.04 & 1.01 & & & & -- & -.06 \\
\hline & CGPY & .06 & 1.02 & & & & & -- \\
\hline
\end{tabular}

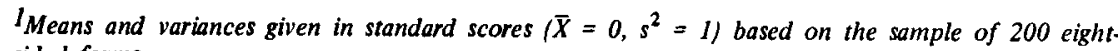
sided forms.

eight-sided random polygons chosen from a larger sample of 200 such patterns. These, in turn, are a subset of 1000 such forms of varying sidedness levels generated in a 100 by 100 unit matrix by a modified Method I procedure (Atteneave \& Arnoult, 1956). These 1000 forms have been quantified on 80 physical measures and the measures have been factored, yielding 12 orthogonal factors of which the first five account for $61 \%$ of the variance of the eight-sided shapes. These first five factors appear to measure the compactness, angularity, horizontal and vertical skew, and elongation of the forms (Brown \& Owen, 1967).

Both samples were selected so that the feature structure in each sample approximated that in the sample of 200 patterns from which they were selected. In order to achieve this objective, one physical measure was chosen to represent each of the first five factors described above (see Table 1). These measures were then standardized, and samples selected by an iterative procedure that minimized the sum of squared deviations of sample feature statistics (means, variances, correlations) from those in the set of 200 from which each sample was drawn. Statistics of the chosen samples are given in Table 2.

\section{Observers}

Ten graduate students, paid for their participation, served as Os. Os were tested individually, in one session of approximately $3 \mathrm{~h}$, and a second session of approximately $1 \frac{1}{2} \mathrm{~h}$.

\section{Procedure, Session 1}

After a familiarization task in which each $O$ viewed the 60 patterns in Sample 1, a series of eight classification tasks was performed. Two-inch-square photographs of the 60 patterns from Sample 1 were placed on a table in random arrangement before the 0 . Correct orientation of each pattern was indicated by a small dot placed above the pattern. The $O$ was instructed to separate the patterns into two groups as homogeneously as possible, with a limitation of approximately equal group size imposed. After the $O$ had completed this task, class membership of all patterns and the O's description of his categories were recorded, and the stimuli were replaced in a random fashion before the 0 . The session then proceeded as before, with sorting into three through nine groups. under the same constraint of approximately equal group size.

\section{Procedure, Session 2}

One week following Session 1; each 0 repeated his three, six, and nine group sorts, to provide a measure of task reliability. He then performed a second sorting task to provide a test of classification rule generality. For each 0 , his five-group sort from Session 1 was reconstructed. The 0 was then asked to place each of the patterns of Sample 2 in the old group in which it best belonged.

\section{Reliability}

\section{RESULTS}

The reliability measure employed was the mean proportion of patterns common to a particular group from Session 1 and its corresponding group from Session 2. Since groups were not necessarily ordered, corresponding groups were identified on a post hoc basis by finding the maximum match for each group from Session 1 by a group from Session 2. Since the sizes of corresponding groups were not necessarily equal for the two sessions, proportions were relative to the maximum number that could be common to both groups. The mean proportions of common patterns per group are shown for each $O$ in Table 3. There it can be seen that there were large individual differences in reliability and that there was an apparent small decrease in reliability with larger numbers of classes. However, the mean proportion of common patterns pooled across Os exceeded chance performance. When an analysis of variance of the arcsin transforms was computed on the deviation between observed proportions and expected proportions, the reliability of the nine-group sort exceeded chance to a greater degree than did either of the other two sorts $(p \leqslant .05)$. This is reasonable in view of the small loss in mean observed reliability and the large drop in expectation associated with going from three to nine groups.

\section{Discriminant Analyses}

For each $\mathrm{O}$, at each sorting level, a stepwise discriminant analysis was performed on the O's classes. Predictors for these analyses were nine physical measures, three of the five measures used to select patterns and six measures chosen on the basis of representativeness of the factor structure of the 80 physical measures and their similarity to, or identity with, measures that have proven predictive of observer behavior in several psychophysical contexts (Aiken \& Brown, 1969a, 1969b. $1969 \mathrm{c}$; Behrman \& Brown, 1968; Brown \& Andrews, 1968). These measures are presented in Table 4. With this stepwise procedure, variables were entered into discriminant equations sequentially on the basis of their ability to increase discriminability among group means, given the presence of the previously entered 
Table 3

Mean Proportion of Common Patterns Per Group

\begin{tabular}{|c|c|c|c|c|c|c|}
\hline \multirow[b]{2}{*}{ Subject } & \multicolumn{2}{|c|}{ Three Groups } & \multicolumn{2}{|c|}{ Six Groups } & \multicolumn{2}{|c|}{ Nine Groups } \\
\hline & Mean & SD & Mean & SD & Mean & SD \\
\hline $\begin{array}{r}1 \\
2 \\
3 \\
4 \\
5 \\
6 \\
7 \\
8 \\
9 \\
10\end{array}$ & $\begin{array}{l}.921 \\
.767 \\
.430 \\
.582 \\
.647 \\
.849 \\
.586 \\
.534 \\
.915 \\
.865\end{array}$ & $\begin{array}{l}.072 \\
.162 \\
.041 \\
.043 \\
.104 \\
.080 \\
.149 \\
.065 \\
.062 \\
.056\end{array}$ & $\begin{array}{l}.325 \\
.664 \\
.642 \\
.520 \\
.441 \\
.706 \\
.533 \\
.680 \\
.668 \\
.717\end{array}$ & $\begin{array}{l}.142 \\
.257 \\
.126 \\
.241 \\
.192 \\
.308 \\
.141 \\
.210 \\
.201 \\
.157\end{array}$ & $\begin{array}{l}.800 \\
.685 \\
.589 \\
.574 \\
.591 \\
.706 \\
.715 \\
.585 \\
.637 \\
.648\end{array}$ & $\begin{array}{l}.125 \\
.244 \\
.239 \\
.207 \\
.249 \\
.283 \\
.213 \\
.228 \\
.262 \\
.186\end{array}$ \\
\hline $\begin{array}{l}\text { Mean } \\
\text { SD } \\
\text { Chance }\end{array}$ & & & & & \multicolumn{2}{|c|}{$\begin{array}{l}.069 \\
.111\end{array}$} \\
\hline
\end{tabular}

Table 4

Measures Used in Discriminant Analyse

\begin{tabular}{|c|c|c|c|}
\hline Measure & & $\begin{array}{c}\text { Factor } \\
\text { Represented }\end{array}$ & $\begin{array}{l}\text { lactor } \\
\text { Loading }\end{array}$ \\
\hline $\mathbf{P}$ & Number of units in the perimeter & Compactness & -.58 \\
\hline $\mathrm{P}_{\mathrm{M} 2 \mathrm{X}}$ & Maximum second perimeter moment of $X$ & Compactness & -.90 \\
\hline $\mathrm{Al}$ & Size of smallest exterior angle & Jaggedness & .87 \\
\hline A $3 I$ & Third moment of interior angles & Jaggedness & -.90 \\
\hline$A_{1}$ & Size of smallest interior angle & Jaggedness ${ }^{1}$ & -.77 \\
\hline $\mathrm{V} / \mathrm{H}$ & Ratio of vertical to horizontal extent & Elongation & .92 \\
\hline $\mathbf{S} / \mathbf{P}$ & Ratio of largest side to perimeter & Side length ${ }^{2}$ & -83 \\
\hline$C G_{X}$ & $\mathrm{X}$ coordinate of areal center of gravity & Horizontal skew & -.89 \\
\hline $\mathrm{CGY}$ & $Y$ coordinate of areal center of gravity & Vertical skew & -.91 \\
\hline
\end{tabular}

${ }^{3}$ A loaded on Factor 7 , a second factor comprised of angle measures, and was chosen due to it prior utility in interpreting dimensions found with this stimulus domain (Aiken \& Brown, 1969b). ${ }^{2} S / P$ loaded on Factor 6, a Factor 6 comprised of measures of side length distribution, and was also chosen due to its prior utility (Aiken \& Brown, 1969b).

variables in the discriminant system. After each step, four indicators of adequacy of classification were computed: (1) $\mathrm{F}$ tests of overall equality of group means based on each variable, given the other variables in the equation, (2) the number of correctly classified patterns, (3) Wilk's Lambda and the $F$ approximation there of, as a test of the null hypothesis of overall equivalence among group means, and (4) F tests of the equality of all possible pairs of group means. As seen below, each indicator yielded positive evidence for the predictability of observer groups by physical feature measures.

For all $O s$ at each sorting level, significant predictors of class membership, were found $(p \leqslant .05)$, satisfying Criterion 1 , above. In order to determine the number of predictors to be used in a particular equation, for the basis of evaluation of the other indicators, several criteria were employed: (1) that the variable be a significant predictor $(p \leqslant .05)$, (2) that predictor inclusion increase correct classification by at least $5 \%$, or that (3) the predictor act as a suppressor variable, causing a previously entered variable to become significant. The mean number of predictors included in observer equations at each sorting level are given in Table 5.
While the number of significant predictors generally increased with sorting level, average accuracy of classification (Criterion 2) varied from approximately $80 \%$ to $50 \%$ as sorting level increased (see Fig. 2). An analysis of variance of the arcsin transformation of the difference between the observed and chance classification proportions in Fig. 2 showed no decrease in relative prediction accuracy as the group levels increased $(\mathrm{F}=1.13$, $\mathrm{df}=7,63$ ). Criterion 3 , i.e., a test of the hypothesis of overall equality of group means, could be rejected for all Os at all sorting levels (for 72 of the 80 discriminant analyses, $p \leqslant .001$, others, $p \leqslant .025$ ). Lastly, while decreasing as sorting level increased, differentiation between specific group pairs exceeded chance at all sorted levels (see Fig. 3)

\section{Feature Utilization}

Given the necessary psychophysical assumption that the physical measures used as predictors in the discriminant equations in some sense map the percejvers' subjective critcria for perceptual classification, then an examination of the discriminant equations in terms of specific measures serves as a procedure for assessing feature utilization. The frequency of times each physical predictor occurred across all
Table 5

Mean Number of Predictors Included in

Discriminant Equations at Each Sorting Level

\begin{tabular}{ccc}
$\begin{array}{c}\text { Number of } \\
\text { Groups }\end{array}$ & $\begin{array}{c}\text { Significant } \\
\text { Predictors }\end{array}$ & $\begin{array}{c}\text { Total } \\
\text { Predictors }\end{array}$ \\
\hline 2 & 1.5 & 1.5 \\
3 & 2.6 & 3.1 \\
4 & 2.4 & 2.8 \\
5 & 2.2 & 2.7 \\
6 & 3.0 & 3.2 \\
7 & 2.8 & 3.1 \\
8 & 2.7 & 3.2 \\
9 & 3.3 & 3.6 \\
Overall & 2.6 & 2.9 \\
\hline
\end{tabular}

${ }^{1}$ These include significant predictors plus suppressors and nonsignificant predictors increasing classification accuracy.

sorts for all Os is summarized in Table 6, with the position in the system in order of differentiating power ( $F$ value in the final discriminant system) indicated. The most predominant predictors were measures of compactness and jaggedness.

In terms of specific combinations of predictive features, feature utilization followed systematic patterns. Based upon the first two measures in a discriminant system, two predominant types of systems may be described: (1) a pure compactness system, in which the first two measures were the compactness measures, i.e., $P$ and $\mathrm{P}_{\mathrm{M} 2 \mathrm{X}}$, and (2) a compactness-jaggedness system, in which the first two measures in the discriminant system were a compactness and a jaggedness measure, i.e., $P$ or $P_{M 2 X}$ and $A_{1}, A_{E}$, or $A_{31}$, respectively. Of the 80 discriminant systems derived ( 10 Os by 8 systems each) $78 \%$ could be described by one of these two classes. In both cases, the observed number of pairings of specific measures exceeded that expected by chance pairings of measures, the latter being based on the number of measure pairs of the $n(n-1)$ possible pairs that satisfy the description of the system. For the compactness and compactness-jaggedness systems, these proportions are $28.6 \%$ observed vs $2.8 \%$

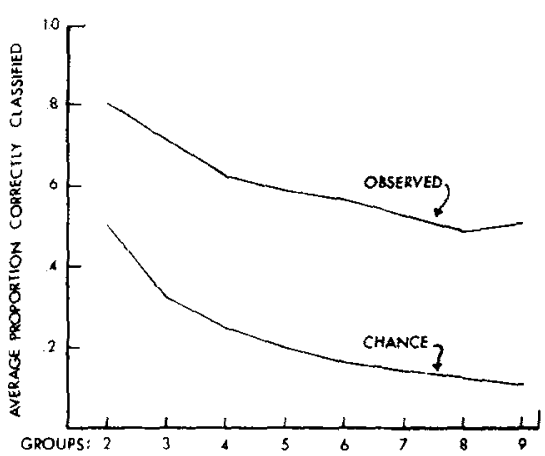

Fig. 2. Mean proportion of pairs of group means differentiated at the .01 and .001 leveis of significance. 
Table 6

Frequency of Occurrence of Specific Variables in Discriminant Systems

\begin{tabular}{|c|c|c|c|c|c|c|c|}
\hline \multirow[b]{2}{*}{ Variable } & \multirow[b]{2}{*}{ Interpretation } & \multicolumn{6}{|c|}{ Position in System } \\
\hline & & First & Second & Third & Fourth & Fifth & All \\
\hline $\mathbf{P}$ & Compactness & 58 & 8 & 2 & 1 & 0 & 69 \\
\hline$P_{M} 2 X$ & & 3 & 15 & 2 & 2 & 0 & 22 \\
\hline Al & Jaggedness & 9 & 14 & 19 & 3 & 2 & 47 \\
\hline $\mathbf{A E}$ & & 3 & 6 & 6 & 4 & 0 & 19 \\
\hline$A_{3 I}$ & & 4 & 17 & 8 & 4 & 1 & 34 \\
\hline $\mathrm{V} / \mathrm{H}$ & Elongation & 0 & 4 & 4 & 1 & 0 & 9 \\
\hline $\mathbf{C G}_{X}$ & Horizontal Skew & 3 & 5 & 0 & 1 & 0 & 9 \\
\hline CGY & Vertical Skew & 0 & 2 & 5 & 1 & 0 & 8 \\
\hline \multirow[t]{2}{*}{$\mathrm{S} / \mathrm{P}$} & Side Length & 0 & 0 & 6 & 8 & 1 & 15 \\
\hline & Total: & 80 & 71 & 52 & 25 & 4 & 232 \\
\hline
\end{tabular}

expected, and $48.5 \%$ vs $16.7 \%$, respectively. Two other possible systems, a pure jaggedness system described by combinations of only angle measures, and an areal skew system described by combinations of an areal skew measure with other measures occurred infrequently, i.e., $8.75 \%$ observed vs $8.35 \%$ expected, and $10.0 \%$ observed vs $30.8 \%$ expected, respectively.

\section{Model Generality}

The generality of equations derived from the 60 patterns to classes based on other patterns from the same domain was examined by fitting the classes constructed from the second sample $(\mathrm{N}=30)$ of patterns with the equations derived from Sample 1. With the exception of one 0 , classification accuracy of the new patterns was only slightly lower than for the original patterns. The mean proportion correctly classified at the original five-group level for the nine consistent $O$ s was .58 , for the new patterns, .51 . For the one exceptional $\mathbf{O}$ the proportion correctly classified dropped from .68 to .13. In summary, it appears that the predictive utility of the model, to the extent that it exists, does generalize to other elements in the same stimulus domain.

\section{DISCUSSION}

The reasonably high reliability of observer sorts across group levels indicates that this type of classification task provides a feasible methodology for dealing with problems of perceptual classification. Moreover, the applicability of a feature utilization model, implemented through the use of the linear discriminant function, appears sound. All indicators of the fit of the model to observer pattern classification were positive, there being, for all Os, physical pattern features that mapped their behavior and hence recovered, to a large extent, the classes they generated. Although individual Os gave widely varying verbal descriptions of the classes they generated, the LDFs constructed on the basis of these classes showed extensive from similarity and discrimination difficulty judgments (Behrman \& Brown, levels of significance.
1968; Aiken \& Brown, 1969b), discrimination latencies (Brown \& Andrews, 1968), and discrimination in noise (Aiken \& Brown, 1969a, 1969c). This same relationship between classification and similarity has been noted when patterns arise from schematic clusters (Aiken, Brown, and Bernstein, 1970).

In previous studies of classification, single-attribute usage was a most predominant strategy. However, in this study only rarely was a single predictor system derived. In only nine of the $\mathbf{8 0}$ systems was this the case; in seven of the nine the single predictor occurred for the two-group sort; in all nine the single predictor was perimeter length. That several predictors typically occurred in a system is probably a function of the type of patterns employed. An $\mathbf{O}$ cannot easily ignore an attribute of the polygon stimuli as he can with stimuli varying discretely in color vs shape, for example.

An interesting source of speculation is the number of predictors that were typically found to be predictive of

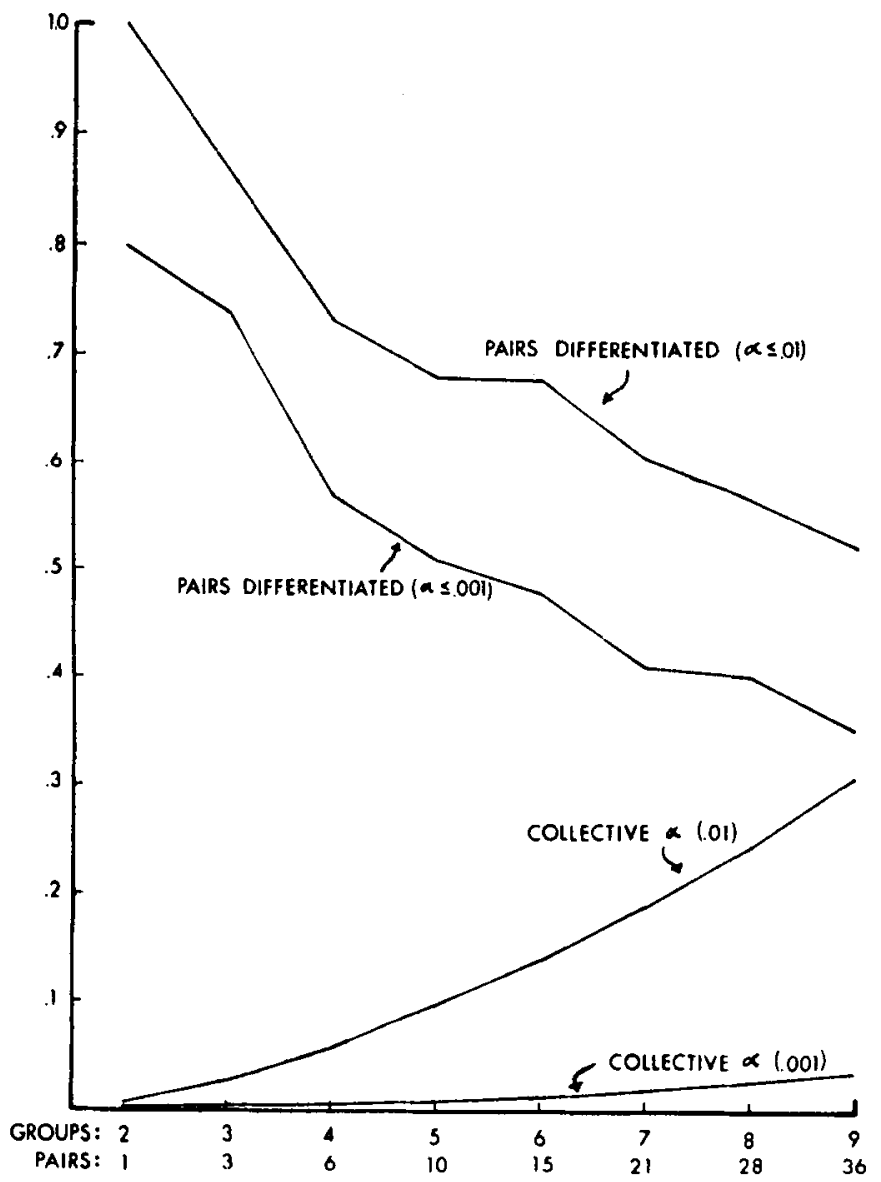

Fig. 3. Mean proportion of pairs of group means differentiated at the .01 and .001 
observer-generated classes. This number is approximately three, the number typically found as the dimensionality of the aforementioned multidimensional spaces. Perhaps we are dealing with another "magic number," which indicates limits on the number of attributes that can be simultaneously used by an $O$ in dealing with a complex multidimensional stimulus domain.

\section{REFERENCES}

AIKEN, L. S., \& BROWN, D. R. Visual form perception: Congruence among spatial configurations. Perception \& Psychophysics, 1969 a, 5, 155-160.

AlKEN, L. S., \& BROWN, D. R. A spatial analysis of the discriminability of forms in noise. Perception \& Psychophysics, 1969b, 5. 171-175.

AIKEN, L. S., \& BROWN, D. R. Visual form perception: Task demands and congruence among spatial solutions. Psychonomic Sciences, 1969c, 15, 219-220.

AIKEN, L. S., \& BROWN, D. R. A feature utilization analysis of the perception of pattern class structure. Perception \& Psychophysics, 1971, in press.

AIKEN, L. S., \& BROWN, D. R., \& BERNSTEIN, R. G. Pattern similarity and class membership: The relationship between perceptual operations. Paper presented at Midwestern Psychological Association meeting. Cincinnati, Ohio, May, 1970.

ATTNEAVE, F., \& ARNOULT, M. D. The quantitative study of shape and pattern perception. Psychological Bulletin, 1956, 53. 452.471.

BEACH, L. R. Cue probabilism and inference behavior. Psychological Monographs, 1964, 78 (5, Whole No. 582).

BEHRMAN, B., \& BROWN, D. R. Multidimensional scaling of form: $A$ psychological analysis. Perception \& Psychophysics, 1968, 4, 19-25.

BERSTED, C. T., BROWN, D. R., \& EVANS, S. H. Free sorting with stimuli clustered in a multidimensional attribute space. Perception \& Psychophysics, 1969, 6, 409-413.

BROWN, D. R., \& ANDREWS, M. H. Visual form discrimination: Multidimensional analysis. Perception \& Psychophysics, 1968. 3, 401-406.

BROWN, D. R., \& BRUMAGHIM, S. H Perceptual equivalence, pattern perception and multidimensional methods. Perception \& Psychophysics, 1968, 4, 253-256.

BROWN, D. R., \& OWEN, D. H. The metrics of visual form: Methodological dyspepsia. Psychological Bulletin, 1967, 68, 243-259.

BRUMAGHIM, S. H., \& BROWN, D. R

Perceptual cquivalence between visual and tactual pattern perception: An anchoring study. Perception \& Psychophysics, 1968, 4, 175-179.

FleNkER, R. M., Jr., \& BROWN, D. R. Pattern perception, conceptual spaces, and dimensional limitations on information processing. Multivariate Behavioral Research, $1969,4,257.272$.

IORSYTH, G. A., \& BROWN, D. R. Stimulus correlates of tachistoscopic discrimination-recognition performance: Compactness, jaggedness, and areal symmetry. Perception \& Psychophysics, 1967, 2, $597-600$.

FORSYTH, G. A., \& BROWN, D. R. Stimulus recognizability judgments as a function of the utility of physical dimensions in recognition-diserimination problems. Perception \& Psychophysics, 1968, 3, 85-88. GARNER, W. R. Uncertainty and structure as psychological concepts. New York: Wiley, 1962.

GARNER, W. R. To perceive is to know. American Psychologist, 1966, 21, 11-19.

GARNER, W. R., \& CLIEMENT, D. E. Goodness ol pattern and pattern uncertainty. Journal of
Verbal Learning \& Verbal Behavior, 1963, 2 , 446-462.

HANDEL, S., \& GARNER, W. R. The structure of visual pattern associates and pattern goodness. Perception \& Psychophysics, 1969 6, 69-72.

IMAI, S. Classification of sets of stimuli with different stimulus characteristics and numerical properties. Perception \& Psychophysics, 1966, 1, 48-54.

IMAI, S.\& GARNER, W. R. Discriminability and preference for attributes in free and constrained classification. Journal of Experimental Psychology, 1965, 69, 596-608.

IMAI, S., \& GARNER, W. R. Structure in perceptual classification. Psychonomic Science Monographs, 1968, 2, (Whole. No. 25), 153-172.

MAVRIDES, C. M., \& BROWN, D. R. Schematic concept formation: Feature measures and constraint redundancy as predictors. Perception \& Psychophysics, 1970, 7 , 239-243. An empirical validation of the concept of coherence. Journal of Experimental Psychology, 1964, 68, 167-170.

RODWAN, A. S. A coherence-criterion in perception. American Journal of Psychology, $1965,78,529-544$.

RODWAN, A. S., \& HAKE, H. W. The discriminant-function as a model for perception. American Journal of Psychology, 1964, 77, 380-392.

ROYER, I:. L., \& GARNER, W. R. Response uncertainty and perceptual difficulty of auditory temporal patterns. Perception \& Psychophysics, 1966, 1, 41-47.

STENSON, H. H. The psychophysical dimensions of similarity among random shapes. Perception \& Psychophysics, 1968, 3, 201-214.

WING, H., \& BLVAN, W. Structure in the classification of stimuli differing on several continuous attributes. Perception \& Psychophysics, 1969, 6, 137-141.

(Accepted for publication May 28, 1970.) 